\title{
A VOZ QUE ECOA NA AMAZÔNIA: SINGULARIDADES NARRATIVAS DE DALCÍDIO JURANDIR
}

\section{THE VOICE THAT ECHOES IN THE AMAZON: NARRATIVE SINGULARITIES OF DALCÍDIO JURANDIR}

\begin{abstract}
Wilson Ferreira Barbosa ${ }^{1}$
RESUMO: Tendo como leituras principais Lukács (1965), Watt (2010) e Bakhtin (2010) para estudar os romances que possivelmente apresentem problemas na sua elaboração, sejam de ordem do conteúdo ou da forma, o romance Chove nos campos de Cachoeira, de Dalcídio Jurandir (1909 - 1979), cuja primeira edição é de 1941, é meu objeto de trabalho. Essa obra em vários momentos foi considerada ora sem qualidades literárias ora elevada ao porte das grandes criações. Mais do que verificar as qualidades e os defeitos desse romance de feição regionalista, que está em sua $8^{a}$. edição, lançada em 2019, o objetivo aqui é realizar uma leitura ampla dos elementos da narrativa para averiguar em que medida esse escritor paraense contribui para a formação da literatura brasileira, em especial da literatura amazônica, e o quanto se inseriu na problemática de sua época, tanto em relação às escolhas literárias quanto a utilização de elementos locais.
\end{abstract}

PALAVRAS-CHAVE: literatura paraense; crítica literária; história literária; Dalcídio Jurandir

ABSTRACT: Having the works of Lukács (1965), Watt (2010) and Bakhtin (2010) as main readings to study the novels that possibly present problems in their elaboration, be they in terms of content or form, the novel Chove nos campos de Cachoeira (first published in 1941), by Dalcídio Jurandir (1909-1979), is the object of this article. Jurandir's novel was at considered a great creation and at times as having no literary qualities whatsoever. More than verifying the qualities and defects of this regionalist novel, which is in its $8^{\text {th }}$. edition, published in 2019, the objective here is to carry out a broad reading of the elements of the narrative to find out to what extent this writer from Pará contributes to the formation of brazilian literature, especially of amazonian literature, and how much he inserted himself into the problems of his time, both in relation to literary choices and the use of local elements.

KEYWORDS: Pará's literature; critic; literary history, Dalcídio Jurandir

\section{Morte e renascimento em Cachoeira do Arari}

O romance Chove nos campos de Cachoeira, do escritor paraense Dalcídio Jurandir (1909 - 1979), é uma obra composta por vinte capítulos, cuja primeira edição se deu em 1941, pela Editora Vecchi e foi escrito entre 1929 e 1939 (SALLES, apud: NUNES, 2006, p. 230). O volume que agora está em minhas mãos é a $8^{a}$. edição, lançado em 2019, pela Pará.grafo Editora. Essa obra é a primeira da série denominada pelo próprio escritor de Ciclo do Extremo

\footnotetext{
${ }^{1}$ Doutorando em Estudos de Literatura no PPG em Letras da UFRGS. Mestre em Teoria da Literatura pela PUCRS. . Pesquisa com apoio Seduc-PA.
} 
Norte, composta por dez livros que narram as ansiedades, os sonhos, as frustrações, os percalços da vida paraense.

Por ordem de publicação as obras dalcidianas são as seguintes: Marajó (1947), Três casas e um rio (1958), Belém do Grão-Pará (1960), Passagem dos inocentes (1963), Primeira manhã (1967), Ponte do galo (1971), Os habitantes (1976), Chão dos lobos (1976) e Ribanceira (1978). E fora do Ciclo do Extremo Norte, saindo da narrativa sobre o povo paraense, o romance Linha do Parque (1959), escrito entre 1950 e 1953, é uma obra sobre o movimento operário ocorrido no Rio Grande do Sul, em 1950.

O enredo de Chove nos campos de Cachoeira se passa na cidade de Cachoeira do Arari, região da ilha do Marajó, no estado do Pará, entre as décadas de 1910 e 1930. Esse período é constatado por alguns dados presentes no próprio livro, como a passagem pela Terra do cometa Halley que aconteceu na madrugada de 18 para 19 de maio de $1910^{2}$ (JURANDIR, 2019, p. 237); bem como o fato de se mencionar a criação da cidade: "Saiu um decreto elevando à categoria de Cidade a Vila de Cachoeira!" (JURANDIR, 2019, p. 337): a fundação da cidade se deu em $31 / 10 / 1935^{3}$.

Há duas personagens que dividem o protagonismo: o garoto Alfredo e seu meio irmão, Eutanázio. Alfredo, um garoto que tem entre 8 e 10 anos de idade, possui um talismã simbolizado por um caroço de tucumã (fruto típico da região amazônica). Talismã tão importante para ele, com poderes mágicos (tal qual a muiraquitã de Macunaíma (2008), de Mário de Andrade), que o autor, no capítulo VIII, dedicou esse capítulo a ele e deu o título de: Caroço de tucumã (outra semelhaça com Macunaíma cujo capítulo XIV tem como título o nome do talismã: Muiraquitã). Esse amuleto tanto funciona como algo que pode realizar os sonhos de Alfredo quanto lhe serve de amigo confidente nas horas de maiores tristezas e solidão.

Essa personagem tem o sonho de sair de Cachoeira do Arari e ir para a capital do estado, Belém, para estudar, uma vez que não consegue vislumbrar um futuro promissor em seu município de nascimento. De acordo com ele, sua cidade não é um lugar bom para se viver; além do que, considera que o sistema educacional se mostra ineficiente. Esse desejo é demonstrado em várias falas suas durante todo o romance, como no excerto a seguir: “-Mamãe, me mande para Belém. Eu morro aqui, mamãe. Cresço aqui e não estudo. Quero estudar, quero

\footnotetext{
${ }^{2}$ SCHULZH, Peter. O cometa e a vacina. Universidade Estadual de Campinas - UNICAMP. Campinas, 29/03/2019. Disponível em: <https://www.unicamp.br/unicamp/ju/artigos/peter-schulz/o-cometa-e-vacina> e <https://pt.wikipedia.org/wiki/Cometa_Halley\#1910> - Acesso em 21 set. 2019, às 12h26.

${ }^{3}$ Dado retirado do site oficial da prefeitura de Cachoeira de Arari, disponível em: <http://cachoeiradoarari.pa.gov.br/omunicipio/sobre-o-municipio/> - Acesso em 24 set. 2019, às $21 \mathrm{~h} 38$.
} 
sair daqui!” (JURANDIR, 2019, p. 231). O estudo é a porta de saída de Cachoeira do Arari e a entrada para uma vida nova cheia de esperanças e prosperidade.

Ao lado de Alfredo está sua mãe, uma mulher preta, casada com um homem branco, condição que levou o garoto a questionar, no início da história, (JURANDIR, 2019, p. 28) o porquê de sua mãe não ter nascida mais clara, mas que imediatamente se dissipa ao lembrar dos cuidados que ela lhe dedica. D. Amélia compartilha do desejo de Alfredo de estudar, e lutará para que isto aconteça, o que é sabido pelo leitor em vários momentos. A seguir, em uma cena em que Major Alberto, pai de Alfredo, discute sobre a criação de patos no chalé, que segundo ele, poderia ser a salvação da economia de Cachoeira do Arari, o narrador expõe o pensamento da mãe de Alfredo:

E mandou, como colaboração, ao Almanaque Agrícola Brasileiro, uma nota sobre a sua criação de patos que leu pra Rodolfo, Bibiano e D. amélia. [...]. D. Amélia era que criava mas Major Alberto tinha a glória. Um filósofo. Devia estar cuidando de mandar o filho para Belém em vez de se meter com planos e catálogos, resmungava D. Amélia. Major queria era estar conversando com ela, lhe interrompendo o serviço... (JURANDIR, 2019, p. 236).

D. Amélia é uma mulher que durante toda a trama está sempre apoiando Alfredo, tentando manter a chama da esperança acesa e confiante de que tudo vai dar certo para que Alfredo possa estudar na capital.

Pode-se dizer que Alfredo é a possível projeção do alterego ${ }^{4}$ de Dalcídio Jurandir, posto que o nome de Alfredo é claramente uma referência, e até uma homenagem ao pai do escritor, também chamado Alfredo. E também é sabido que o escritor concluiu os estudos primários em Belém.

Já o outro protagonista, Eutanázio, com quase 40 anos, irmão de Alfredo, filho do primeiro casamento do Major Alberto, tem uma vida sem sucesso e recheada de sofrimentos, tornando-se uma pessoa sem sensibilidade, mal educada, ranzinza e frustrada. Possui algum estudo e gosta de literatura e também se arrisca a compor poemas. Todas essas características colocam em foco uma personagem antagônica cuja vivência e mentalidade são portadoras da conotação da falência moral, social e econômica tanto quanto é um ser de consciência crítica a respeito do momento político e do declínio por que passa a sociedade de Cachoeira do Arari, na primeira metade do século XX.

Eutanázio leva uma vida com uma doença que lhe consome aos poucos, "misteriosa moléstia essa que parecia invadir todo o chalé”, que era provavelmente a sífilis, e apenas

\footnotetext{
4 "Literariamente é possível definir o alterego como a identidade oculta de um ser fictício ou como um artifício do autor de um livro para se revelar ao leitor na pele de um personagem, de forma discreta e indireta. Em geral ele apresenta muitas das características de seu criador, as quais podem ser descobertas em uma análise mais profunda." Disponível em: https://www.infoescola.com/literatura/alter-ego/ - Acesso em 23 set. 2019, às 11h53.
} 
aguarda o momento de sua morte, como sugere o seu próprio nome ${ }^{5}$. A “autorização" para sua morte se dá com a presença de Irene, mulher por quem era apaixonado. Essa "sentença" é confirmada na fala de D. Amélia, sua madrasta: “- Olha, D. Tomázia, Eutanázio só morre se a senhora trouxer Irene aqui para ver ele... [...] - Traga ela. Faça tudo. Ela vem. Enquanto ela não vem ele não fecha aqueles olhos. Isso é horrível, D. Tomázia.” (JURANDIR, 2019, p. 342 343). E após a mulher tão amada por Eutanázio fazer sua visita, finalmente ele pôde dizer adeus ao mundo que tanto lhe decepcionou, que tanto mal lhe causou.

Quanto às demais personagens, estão na obra para reforçar a personalidade e o caráter dos dois protagonistas. O antagonismo é representado pelo pai, Major Alberto Coimbra, secretário da Intendência, um homem que conhece literatura, branco, tem consciência da exploração da mão de obra do povo trabalhador de Cachoeira. Major Alberto não se empenha em fazer algo para que Alfredo vá estudar em Belém e ao mesmo tempo se mostra alheio às dificuldades que Eutanázio enfrenta; ou seja, não apresenta nenhuma solução para os problemas de ambos os filhos.

\section{E o "Dom Casmurro"e "Machado de Assis" vão para...}

Em 1941, um ano após Dalcídio Jurandir ter recebido o prêmio Vecchi-Dom Casmurro, esse que era um dos maiores concursos da época e que o lançou no mercado literário, obteve críticas que ora o menosprezavam ora o elogiavam, como a de Álvaro Lins (in: BARBOSA, 2016, p. 70 - 74). Em seu posicionamento, Álvaro Lins afirma desconhecer os critérios de avaliação das obras ao mesmo tempo em que lança um olhar irônico e sarcástico a respeito do concurso; de acordo com suas palavras: "Também ignoro qual dos dois critérios (ambos lícitos), o júri seguiu: se o de premiar os melhores romances, ou se premiar os menos ruins dos que se apresentaram...". Com essa asserção o crítico desmerece não só a forma como o certame foi realizado como também os próprios concorrentes que venceram; e ao fazer esse julgamento, até mesmo a competência dos avaliadores é alvo de seus aviltamentos.

Entretanto, no decorrer de seu discurso, Álvaro Lins, embora tenha um ponto de vista até mesmo preconceituoso, ele ainda prevê um futuro auspicioso para Dalcídio Jurandir: “O que falta ao livro do Sr. Dalcídio Jurandir é a realização literária, é o domínio do material romanesco, é a consciência mesma da sua obra. Não sendo um romance de valor, sobretudo de valor literário, Chove nos campos de Cachoeira revela indícios de um romancista.” No ponto

\footnotetext{
${ }^{5}$ Eutanásia: 1. morte serena, sem sofrimento; 2. ação sem amparo legal, para antecipar a morte de um indivíduo que está com uma doença incurável ou em estado terminal. Conceito adaptado de: FERREIRA, Aurélio Buarque de Holanda. Novo dicionário Aurélio da língua portuguesa. $4^{\text {a }}$. ed. Curitiba: Positivo, 2009.

${ }^{6}$ Prêmios recebidos por Dalcídio Jurandir em 1940 e 1972, respectivamente.
} 
de vista do crítico, o escritor paraense precisa percorrer um longo caminho para obter êxito em sua trajetória de romancista.

Diante da proposição de Álvaro Lins, podemos traçar um paralelo com as palavras de Ian Watt (2010, p. 15) quando este discorre a respeito do romance de Daniel Defoe, um dos iniciantes do romance inglês no início do século XVIII: "Quando começou a escrever ficção, Defoe não deu grande atenção à teoria crítica predominante em sua época, a qual ainda se inclinava para os enredos tradicionais; ao contrário, deixou a narrativa fluir espontaneamente...”. Com essa afirmação Ian Watt declara que Defoe compôs uma obra diferente dos padrões tradicionais considerados elevados, superiores, e passou a escrever conforme "sua própria concepção de uma conduta plausível das personagens." (WATT, 2010, p. 15). Assim, ao invés de seguir a convenção do passado em que havia personagens e locais que representavam tipos universais, a ficção deveria ser a representação de aspectos, localização e personagens de acordo com a visão de mundo do ficcionista.

Justapondo as proposições de Álvaro Lins e de Ian Watt, voltemos para o romance Chove nos campos de Cachoeira. É um livro que apresenta uma visão particular de seu escritor, posto que as personagens possuem características peculiares e pertencem a épocas situadas no espaço e no tempo: compõem o retrato do povo paraense entre as décadas de 1910 e 1930. Mesmo diante do fato da obra não possuir todas as qualidades literárias, segundo a visão de Álvaro Lins, o livro de Dalcídio Jurandir possui os atributos de literatura regionalista, criando a paisagem e o linguajar próprios do povo paraense com seus costumes, mitos, religiosidade; e assim tem-se um romance concebido de acordo com os padrões provindos da imaginação, da criação do escritor paroara, e permite que o leitor tenha uma visão realista da paisagem, da população, das crendices e da cultura. Com apresentação desse quadro, as palavras de Ian Watt (2010, p. 11) a respeito do ato criativo de Defoe, também fazem sentido a respeito da criação de Dalcídio Jurandir: "seu realismo não está na espécie de vida apresentada, e sim na maneira como a apresenta". Um panorama amazônida desvendado sob a perspectiva de quem vivenciou e rememora épocas de sofrimentos e enfortúnios.

Isto posto, os acontecimentos presentes na narrativa por vezes não são ideias baseadas nas composições tradicionais, são "ou inteiramente inventados ou baseados parcialmente num incidente contemporânceo." (WATT, 2010, p. 15), como no momento em que Alfredo perde seu talismã, o caroço de tucumã, e tem que procurar outro: "Agora tem que ir ao tanque escolher outro caroço que fale como o outro, lhe mostre os campos de Holanda...” (JURANDIR, 2019, p. 26). Essa ação mostra uma personagem que, por causa da sua solidão, busca uma companhia num objeto inanimado, uma vez que o caroço será a corporificação de seus desejos, de seus 
sonhos. Dessa forma, Dalcídio Jurandir escreve um romance com características marcantes da cultura paraense, com fatos que fizeram parte da sua infância, conjuntamente com vários outros eventos que foram explicitamente inventados, conforme exemplos já mencionados.

Álvaro Lins teceu críticas do ponto de vista da estilística, da estética, bem como “também refletirá intensamente o instante político" (in: COUTINHO, 2004, p. 624), pois levou em consideração, sobretudo, as caraterísticas liguísticas do escritor, bem como o seu posicionamento político-partidário, que são particularidades que diferenciaram o romancista paraense das normas que eram prescritas pela crítica, até então, vigentes. A linguagem utilizada por Dalcídio Jurandir era a falada na região da ilha do Marajó o que tornou singular a sua escrita em relação aos seus contemporâneos, cultivando uma tradição regionalista, intimista e autobiográfica.

Diante dessas afirmações, podemos reconhecer Dalcídio Juradir utilizando-se do discurso monológico, posto que esse discurso "é um ato puramente individual, uma expressão da consciência individual, dos seus propósitos, intenções, impulsos criativos, gosto e assim por diante" (VOLÓCHINOV, 2017, p. 202), deu vida a uma obra cujas características particulares lhe conferem o título de "o maior romancista da Amazônia do século XX", nas palavras de Gunter Karl Pressler, professor e pesquisador da UFPA (BOLLE, 2010, p. 235 - 259).

Para alguns críticos contemporâneos ao escritor paraense, pode ser que o seu romance tenha desencaminhado das normas consideradas perfeitas e concretas naquele momento. No entanto, a capacidade em escrever uma obra com estilo próprio, principalmente ao que se refere à composição linguística, posto que Dalcídio Jurandir lança mão de um vocabulário próprio do povo paraense, muito especificamente do período entre 1929 e 1941, fase da escritura e publicação do livro, lhe conferiu um dos maiores prêmios da Literatura Brasileira da época, mesmo que a crítica em algum momento tenha classificado como um romancista que ainda estava em processo de descoberta de si mesmo, de descoberta de seu ofício de escritor, e por extensão, seu livro foi avaliado como um romance mal elaborado e destituído de valor literário; em outras palavras, a crítica parecia estar diante de um romance que classificava como ruim.

Se caso Dalcídio Jurandir não houvesse composto uma obra original, distanciando-se dos padrões apregoados pelos críticos da época, então estaria seguindo um modelo estético emoldurado, acompanharia um protótipo literário sem nenhuma inovação. Sua obra, então, seria como diria Jean-Paul Sartre (2015, p. 123): "Digo que a literatura de determinada época é alienada quando não atingiu a consciência explicíta de sua autonomia e se submete aos poderes temporais ou a uma ideologia, isto é, quando considera a si mesma como meio e não como fim 
incondicionado." Sartre julga que a Literatura deva considerar a historicidade, que é o momento em que leitor e escritor pertencem a uma mesma realidade, uma mesma época.

Para Sartre, romancista e leitor coadunam do mesmo período histórico e, portanto, conhecem os mesmos fatos, inclusive compartilham da mesma linguagem, do mesmo vocabulário e dos mesmos problemas. Por conseguinte, o escritor paraense valeu-se de sua escrita para comunicar eventos conhecidos por seus contemporâneos, e em especial conhecidos pelo homem da amazônia paraense, distanciando-se de fórmulas e modelos de escrita. Logo, desse ponto de vista, Dalcídio Jurandir pode ser considerado um escritor engajado, posicionado social e politicamente, tendo sua voz ampliada ao fazer as denúncias contra uma sociedade hipócrita, egoísta que vivia de aparências. Em meio às personagens egocêntricas, há de se fazer um resguardo apenas a D. Amélia, mãe de Alfredo, única personagem de Chove nos campos de Cachoeira que sempre foi preocupada com o outro, sempre nutriu o sentimento de altruísmo.

A despeito da recepção no meio crítico não ter sido uma das melhores, Dalcídio Jurandir conseguiu mostrar o valor da sua narrativa, posto que está na $8^{\mathrm{a}}$. edição. Neste sentido, compartilho o pensamento de Georg Lukács (1965, p. 53) sobre os novos estilos:

Todo novo estilo surge como uma necessidade histórico-social da vida e é um produto necessário da evolução social. Mas o reconhecimento do caráter necessário da formação dos estilos artísticos não implica, de modo algum, que esses estilos tenham todos o mesmo valor e estejam todos num mesmo plano. A necesidade pode ser, também, a necessidade do artisticamente falso, disforme e ruim.

O ato criador de Dalcídio Jurandir é realizado por muitas vias, além do emprego da linguagem específica da região cachoeirense, utiliza um código linguístico que harmoniza conotação e denotação, como se pode ver a seguir:

a) construções frasais com expressões corrompidas: "- Aquilo disque desce com a gente, vem..." (JURANDIR, 2019, p. 272);

b) semântica própria: “Eras daquele homem!” (JURANDIR, 2019, p. 106);

c) léxico único: "perna tuíra” (JURANDIR, 2019, p. 97);

d) a reprodução da fala: “- Vou te comê de espeto.” (JURANDIR, 2019, p. 27).

A criação literária de Jurandir também é desenvolvido por meio da transposição biográfica de suas inquietações da infância (incorporada na visão da personagem Alfredo) tanto do passado como do presente (também pelo ângulo da personagem Eutanázio). Tudo contado por um narrador que conhece a vida das personagens que surgem na trama, desde os seus medos mais íntimos aos seus mais profundos sonhos, os que podem ser benéficos ou causar-lhes os piores males no futuro. 
Logo, o romancista paraense faz parte de um conjunto de escritores que concebe sua obra com uma força e particularidade extremamente intrísecas, íntimas e intimistas, pertencente a um universo Modernista em que se mesclam o Naturalismo e a linguagem fluida, o que torna o seu trabalho ímpar em sua época, por trazer à tona uma realidade rural, bem diferente da dos grandes centros urbanos.

Ainda na esteira da linguagem utilizada por Dalcídio Jurandir, faço uso das palavras de Mikhail Bakhtin (2010, p. 400), quando ele certifica que os romances "são largamente penetrados pelo riso, pela ironia, pelo humor [...], o romance introduz uma problemática, um inacabamento semântico específico e o contato vivo com o inacabado, com a sua época que está se fazendo (o presente ainda não acabado)"; e mais: que esse inacabamento foi absorvido pelo romance que "é o único gênero em evolução"; diferente da epopeia, que possui o aspecto de um gênero emoldurado, finalizado, acabado, solidificado, existente há um longo tempo e que, portanto, permanece no passado; o romance, ao contrário, é um gênero ainda em estado de formação, sem características fixas, que incorpora a condição de ser algo inacabado.

No gênero romanesco, há uma abertura para tratar de todos os assuntos, todo o tipo de personagem pode aparecer, há histórias de amor ou apenas descrições do cotidiano humano. $\mathrm{Na}$ perspectiva de Bakhtin o romance é uma história de gente comum, o centro da narrativa não está na ideia de indivíduo como sendo o herói. O escritor pode descrever um acontecimento real, autêntico ou apenas referir-se a esse acontecimento utilizando metáforas, ou enfocá-lo de forma alegórica. Em resumo, somente esse gênero é capaz de refletir de maneira mais completa e consegue tratar a realidade como matéria complexa e com diferentes possibilidades expressivas.

Para confirmar as palavras do estudioso russo, verificando na obra dalcidiana, transcrevo a resposta no diálogo entre Alfredo e as parteiras que estavam auxiliando D. Amélia a dar à luz a sua irmã. As parteiras fizeram várias perguntas ao menino a respeito de como ele imaginava que sua irmãzinha havia nascido, e depois de várias respostas ingênuas e que elas faziam questão de negar, o narrador relata o seguinte: “Aí o menino disfarçou, deu as costas e arriscou: - Então veio pela bunda!” (JURANDIR, 2019, p. 243). Nesse trecho, vê-se a ironia, o sarcasmo, o humor que Dalcídio Jurandir deixa passar para o leitor e que de certa forma era uma linguagem que os críticos contemporâneos ao livro Chove nos campos de Cachoeira não conseguiam admitir, por ser uma mistura entre ingenuidade e astúcia, ignorância e humor. Para Bakhtin, a obra romanesca está sempre evoluindo e apreendendo a realidade tal qual ela é em seus movimentos: "não existe uma linguagem e estilos únicos no romance. Ao mesmo tempo 
há um centro linguístico verbal-ideológico do romance.” (BAKHTIN, 2010, p. 370). A linguagem romancesca é aquela que contamina, que renova, que transforma toda a literatura.

E o próprio posicionamento de Dalcídio Jurandir tem muito a dizer sobre o ato criativo do romancista brasileiro:

\begin{abstract}
Agora cabe também ao romancista brasileiro, dentro de seu ramo, de sua especialidade, reunir os materiais, tombar os patrimônios de nossa vida histórica, política, marcar as áreas de uma sensibilidade e de uma imaginação. Ao romancista convém não perder jamais o contacto com as mais miúdas anotações da realidade brasileira. Costumes, linguagem, lendas, o quotidiano do trabalho e da vida religiosa, profana, política e das atividades ideológicas de nosso povo, tudo isto deve impressionar sempre o romancista (NUNES, 2006, p. 182).
\end{abstract}

Mikhail Bakhtin (2010, p. 407) afirma que “a memória, e não o conhecimento, é a principal faculdade criadora e a força da literatura antiga. [...]. A experiência, o conhecimento e a prática (o futuro) definem o romance." Assim, enquanto a literatura do passado (a epopeia) mantém uma tradição imutável, chamada inclusive de "passado absoluto", que revive tudo a partir da memória, e procura demonstrar que nesse passado tudo é bom, o romance é a forma que desfaz a concepção de não aceitar a relativização do mundo; ou seja, a obra romanesca é projetada a partir do ponto de vista individual do autor, sua criação admite analisar e revelar o mundo tal qual ele enxerga, não apenas a partir do relato de fatos revelados por meio da transcrição e transmissão das lembranças de uma nação, como é o caso da epopeia.

Ademais, na trama romanesca, em todas as ações das personagens sempre haverá circunstâncias, situações, conhecimentos de mundo que serão passíveis de críticas e, segundo Sartre (2015, p. 90), os elementos que podem sofrer essas críticas são: "as instituições, as superstições, as tradições, os atos de um governo tradicional”. Dalcídio Jurandir está vinculado a um grupo de escritores que, ainda segundo Sartre (2015, p. 90), possui uma "posição crítica por essência" e por isso, é preciso que ele (o escritor) tenha "alguma coisa a criticar". Portanto, o escritor paraense denunciou o seu tempo presente, que, a meu ver, é o que mais importa, e o tempo que logo passa. Além disso, sem dúvida alguma, apresentou em sua obra as críticas que concluiu serem necessárias, a partir da sua visão de mundo, dos seus interesses pessoais, do seu posicionamento político; dito de outro modo, pode-se inferir que tudo aquilo que estivesse ao redor de sua vida era motivo para ser registrado em seus romances.

E mais: "O romance está ligado aos elementos do presente inacabado que não o deixam se enrijecer. O romancista gravita em torno de tudo aquilo que não está ainda acabado. [...] pode representar os momentos reais da sua vida ou fazer uma alusão, pode se intromenter na conversa dos personagens..." (BAKHTIN, 2010, p. 417). O romancista recolhe tudo que necessita para 
desenvolver a sua obra (dados da sociedade, da religião, da política, da educação, dos comportamentos, da cultura, do fazer artístico) seguindo o caminho da experiência vivida, a partir dessa ideia da "atualidade inacabada"; nada no romance está finalizado, há sempre algo a desvendar. Como não se trabalha mais com totalidades, sempre existirá no espaço narrativo um problema que ainda não obteve solução.

Considerando todos esses elementos, a respeito de como se constrói um romance, e somando ao que diz Walter Benjamin (1980, p. 60): “O narrador colhe o que narra na experiência, própria ou relatada. E transforma isso outra vez em experiência dos que ouvem sua história”, Dalcídio Jurandir valeu-se de sua vivência, de suas experiências pessoais, de suas investigações, de suas observaçoes axiológicas e nos desvenda um passado a respeito do mundo marajoara, não um passado absoluto, mas um passado questionável, com os pontos de vistas do escritor, que reavalia este passado e questiona os modos de vida. Ele desnuda ao leitor uma obra que é um modo de ver e de escrever a vida paraense, as mazelas e os obstáculos que talvez o próprio autor tenha experimentado e projetado na linguagem e nas formas romanescas.

Para dar vida a Chove nos campos de Cachoeira, Dalcídio Jurandir pesquisou sobre o passado, as crendices, a política, a geografia, suas lembranças pessoais; ele fez um estudo a respeito de tudo o que fosse possível sobre o povo paraense e que pudesse expor e transmutar em seu romance. De forma geral, o próprio autor se expresou sobre sua obra: "Uma das coisas que considero válidas na minha obra é a caracterização cultural da região. Acumulei experiências, pesquisei a linguagem, o falar paraense, memória, imaginação, indagações.” (NUNES, 2006, p. 180). Dessa maneira, Jurandir reafirmou o que disse Lukács (1965, p. 55): "Não existe uma "maestria" separada e independente de condições históricas, sociais e pessoais que sejam adversas a uma rica, vívida e ampla reprodução da realidade objetiva". A obra literária pode, portanto, apresentar os problemas sociais, os conflitos enfretados pelo ser humano, relacionando as personagens com os objetos e acontecimentos que circulam no ambiente. Nada em Chove nos campos de Cachoeira é por acaso, todas as ações são manifestações da consciência humana diante das interrogações que a realidade impõe e que o escritor traduz em linguagem.

É com um narrador heterodiegético que entramos no mundo paraense revelado por Dalcídio Jurandir. Um discurso narrativo vai nos mostrando as personagens, todas envoltas em nebulosidade, de uma época que encontrava em estado de degradação. Um dos aspectos muito relevantes em Chove nos campos de Cachoeira é a crítica à sociedade cachoeirense que apesar de sua decadência social, moral e política, que mesmo passando fome, ainda procura manter uma aparência, algo que é insustentável, como na cena em que Eutanázio faz uma visita a 
Domingão e testemunha a miséria daquela família: “Uma vez, Eutanázio foi encontrá-los [...] com a mesa arrumada, alguns pratos antigos e caros, uma terrina branca e alta, dois copos cheios d'água. A terrina vazia, os pratos vazios e pelo corredor se podia ver o fogão apagado." (JURANDIR, 2019, p. 222). É o quadro da família da Amazônia, da primeira metade do século XX, em ruínas, pois é vítima da crise econômica causada pelo declínio do ciclo da borracha?

Os dramas centrais que atravessam todo o livro, como já dito antes, são: a vida desventurada da personagem Eutanázio, que não vê solução para seu martírio, o seu destino inexorável, que é enfocado em simultâneo à busca de uma existência baseada em um futuro melhor, na visão do menino Alfredo. Todas as demais personagens têm suas ações construídas em favor desses dois irmãos, que no meu ponto de vista, constituem uma alegoria do homem duplo que há em Dalcídio Jurandir: de um lado, o homem desacreditado nas ideias de uma sociedade consumista, capitalista e egoísta; e de outro, o que carrega a esperança de uma vida melhor que pode surgir com os ideais marxistas, e com o Comunismo, partido ao qual o autor era filiado e que, por conta disso, esteve preso por duas vezes. Realidade e fantasia, naturalismo e modernismo, frustrações e desejos, capitalismo e comunismo, toda realidade binária, todas as contradições fazem parte do universo criativo da dialética dalcidiana.

Alfredo e Eutanázio possuem características completamente opostas; são protagonistas com personalidades bem distintas. Alfredo pretende uma outra vida, um outro futuro, longe de seu lugar de origem, pois não se conforma com a realidade em que vive, tanto a realidade geográfica quanto a humana. Debate-se com as crianças, com os adultos, com a natureza, com tudo o que faz parte da sua convivência. "Seu terror era ter de ficar naqueles campos como José Calazãs. [...] Alfredo quer fugir daquela coruja como deseja fugir de Lucíola, do chalé, de Cachoeira." (JURANDIR, 2019, p. 247). O horizonte delineado por ele é algo bem diferente do que vive, não deseja uma vida fantasiosa, mas ambiciona algo real e possível de alcançar. $\mathrm{O}$ que será possível por meio do estudo, do conhecimento.

Já Eutazánio aceita seu futuro lúgubre e não procura remediá-lo, sua vida resume-se em tentar conseguir o amor de Irene, mesmo sabendo que jamais conseguirá tal proeza. "Dirá, de novo, que não tem roupa, lhe faltam camisas, o que seria disfarçar a necessidade que tem de falar sobre Irene...” (JURANDIR, 2019, p. 227). Além do amor impossível, Eutanázio espera apenas a morte.

\footnotetext{
${ }^{7}$ De acordo com Ricardo Bueno: "Em Janeiro de 1910, o mundo industrial foi subitamente acometido de grave crise de "febre" da borracha. [...] Nas palavras de Bárbara Weinstein, "essa queda, longe de um simples interlúdio, acabou sendo o começo de uma decadência de dez longos anos que iria aleijar a economia extrativista da Amazônia". [...] A crise se manifestou na falência das casas aviadoras, na queda da produção dos seringais, no caos das finanças públicas." (BUENO, Ricardo. Borracha na Amazônia: as cicatrizes de um ciclo fugaz e o início da industrialização. Porto Alegre: Quattro Projetos, 2012).
} 
Logo, essas duas personagens não possuem a capacidade de se hamonizarem com a sociedade. Seus mundos são despedaçados e por isso não podem alcançar uma realidade em que possam se sentir satisfeitos, pois ambas estão em completo desacordo com a sua comunidade. Os desejos de cada um dos protagonistas são imbuídos de ideologias que os diferem das demais personagens. Aquelas personagens secundárias, antagonistas, servem aliás, para promoverem Alfredo e Eutanázio; ou seja, todas as personagens fazem com que os dois protagonistas ganhem mais destaques no interior da trama. A exemplo de Lucíola, que se julga mãe adotiva de Alfredo, mas que não tinha a atenção do menino: "E Lucíola contemplava-o, com amargura e enlevo ao mesmo tempo, o filho de seu coração, seu filho de titia." (JURANDIR, 2019, p. 136). No caso de Eutanázio, há D.Gemi, mulher que tentou ajudá-lo a superar a enfermidade que o acometia: “Estava em casa de seu pai feito um parasita, doente e aquela velha Gemi a persegui-lo" (JURANDIR, 2019, p. 39). Em suma: Lucíola e D. Gemi, aparecem apenas para que os protagonistas tenham maior relevância.

Poucas são as descrições em Chove nos campos de Cachoeira, uma vez que ao narrador o que mais importa são as sequências que marcam todo o percurso a respeito das ações patológicas humanas, sejam elas físicas ou psíquicas. Tudo na natureza favorece uma atmosfera de tristeza e dor: "Chove. O vento zune. A chuva bate com violência nas janelas do chalé. [...] Por que Eutanázio não voltou ainda? Será que aguenta ainda mais uma daquelas doenças? [...] Eutanázio paralítico, os olhos revirados [...], gemia, chamando o pai.” (JURANDIR, 2019, p. 81). O que prevalece na obra é uma narração que ora é lenta e maçante ora é rápida e agradável, fazendo com que a leitura tenha sua própria fluidez, como a chegada e o término de uma chuva.

Essas particularidades podem ser justificadas a partir da posição de Lukács (1965, p. 72), pois, para o teórico, a descrição é “absolutamente supérflua”, não há nada de poético numa descrição se não tiver um efeito direto na ação que é narrada. As paisagens que são descritas em Chove nos campos de Cachoeira auxiliam na composição do estado psicológico de cada personagem, como na descrição do ambiente natural de Cachoeira do Arari logo após a queimada dos campos: “A vila caía num sono como uma menina doente. Por que sua mãe não resolvia logo o caso do colégio? Alfredo não sabia que voltava com a escura solidão dos campos queimados, estava mole, com um indefinido esmorecimento." (JURANDIR, 2019, p.26). A imagem dos campos queimados faz com que a tristeza tome conta de Alfredo, aumentando seu desejo de sair de Cachoeira do Arari para estudar na capital.

Ao chegar ao fim desta análise do romance dalcidiano, tentei seguir um caminho contrário ao que vários críticos fizeram, por entender que Dalcído Jurandir traçou um itinerário que o faz merecedor de reconhecimento nos dias atuais. Das onze obras que escreveu, várias 
delas já tiveram suas republicações e, certamente, o romancista paraense segue o trilho de uma escrita que é original, de acordo com o que afirma Ian Watt (2010, p. 13): “o romance é o veículo literário lógico de uma cultura que, nos últimos séculos, conferiu um valor sem precedentes à originalidade, à novidade". Pode-se buscar os traços dessa originalidade na opção pelo uso da linguagem regionalista paraense do início do século $\mathrm{XX}$, pelo recorte feito na cultura marajoara, pela exposição da religiosidade e do misticismo que cerceia toda uma comunidade, pelo retrato da paisagem inigualável; e, sobretudo, por evidenciar a riqueza da alma humana, não somente a do homem amazônida, mas a do homem brasileiro. A singularidade desse escritor paraense já está tão reconhecida que hoje vários pesquisadores se ocupam da obra completa de Dalcídio Jurandir, sempre destacando que a Literatura Brasileira tem um escritor que ecoa sua voz na e da Amazônia.

\section{REFERÊNCIAS}

ANDRADE, Mário de. Macunaíma: o herói sem nenhum caráter. Rio de Janeiro: Agir, 2008.

BAKHTIN, Mikhail. Questões de literatura e de estética: a teoria do romance. São Paulo: Hucitec, 2010.

BARBOSA, Wilson Ferreira. A recepção crítica da obra de Dalcídio Jurandir: Rio de Janeiro e Belém do Pará (1940 - 1980). 2016. Dissertação (Mestrado em Letras) - Programa de PósGraduação em Letras, Pontíficia Universidade Católica do Rio Grande do Sul, Porto Alegre, 2016.

BENJAMIN, Walter. Textos escolhidos. (Coleção Os pensadores). São Paulo: Abril Cultural, 1980.

BOLLE, Willi. (org.). Amazônia: região universal e teatro do mundo. São Paulo: Globo, 2010.

COUTINHO, Afrânio. A literatura no Brasil. Vol. 5. 7ª edição. São Paulo: Global, 2004.

GALLAGHER, Catherine. Ficção. In: MORETTI, Franco (org.). O romance 1: A cultura do romance. São Paulo: Cosak Naify, 2009. p. 629 - 658.

JURANDIR, Dalcídio. Chove nos campos de Cachoeira. 8ª edição. Bragança: Pará.grafo Editora, 2019.

LUKÁCS, Georg. Ensaios sobre Literatura. Rio de Janeiro: Civilização Brasileira, 1965.

NUNES, Benedito; PEREIRA, Ruy; PEREIRA, Soraia Reolon. Dalcídio Jurandir: romancista da Amazônia. Belém: SECULT; Rio de Janeiro: Fundação Casa de Rui Barbosa/Instituto Dalcídio Jurandir, 2006.

SARTRE, Jean-Paul. Que é a literatura? Trad. Carlos Felipe Moisés. Petrópolis: Vozes, 2015. 
VOLÓCHINOV, Valentin. Marxismo e filosofia da linguagem: problemas fundamentais do método sociológico na ciência da linguagem. São Paulo: Editora 34, 2017.

WATT, Ian. A ascensão do romance: estudos sobre Defoe, Richardson e Fielding. (1957) Trad. Hildegard Feist. São Paulo: Companhia das Letras, 2010.

Recebido em 18/05/2020. Aceito em 11/09/2020. 